\title{
THE IMPLEMENTATION OF THE EDUCATIONAL FUNCTION OF WITNESS INTERROGATION AS AN ELEMENT OF COUNTERING CRIMES OF EXTREMISM
}

\author{
Olga A. Slavgorodskaya \\ Saratov State Academy of Law, Saratov, Russian Federation
}

\begin{abstract}
Introduction: countering crimes of extremism is one of the most urgent tasks of our time. To solve this problem, a variety of tools and methods are actively used, including the capabilities currently developed by criminalistics. One of the promising directions in the development of improving measures to counter extremism is the formation of a morally oriented personality. In this regard, the purpose of the study was to consider the possibilities of educational influence on witnesses during interrogation in criminal cases of extremism. Methods: the methodological framework for this research was based on the methods of systematicity, analysis, historicism and comparative law. Results: the author's well-grounded position was based on the consideration of the possibility of using educational influence on various categories of witnesses in the investigations of crimes of extremism. In the study of the possibilities of using educational effects, the relationship between the influences of the investigator on the witness was studied. On the basis of the conducted research, the differentiation of characteristic categories of witnesses subject to interrogation in this category of criminal cases under investigation was made. The author studied the peculiarities of forming professional competencies of investigators and the possibilities of using their key elements to make a positive impact on witnesses. Based on the analysis of the basics of interrogation tactics, the place of psychological contact was determined as an element that helps to strengthen the positive impact on the witness during the interrogation. Conclusions: as a result of the research, the existing relationship between the educational influences exerted by the investigator during the interrogation of witnesses in the investigation of crimes of extremism was revealed. It was established that educational influence could be used as one of the measures to counteract this type of crime.
\end{abstract}

Key words: educational influence, witness interrogation, information, psychological contact, investigation of crimes, witness, investigator.

Citation. Slavgorodskaya O.A. The Implementation of the Educational Function of Witness Interrogation as an Element of Countering Crimes of Extremism. Legal Concept, 2020, vol. 19, no. 2, pp. 64-70. (in Russian). DOI: https://doi.org/10.15688/lc.jvolsu.2020.2.9

\section{РЕАЛИЗАЦИЯ ВОСПИТАТЕЛЬНОЙ ФУНКЦИИ ДОПРОСА СВИДЕТЕЛЯ КАК ЭЛЕМЕНТА ПРОТИВОДЕЙСТВИЯ ПРЕСТУПЛЕНИЯМ ЭКСТРЕМИСТСКОЙ НАПРАВЛЕННОСТИ \\ Ольга Александровна Славгородская \\ Саратовская государственная юридическая академия, г. Саратов, Российская Федерация \\ Введение: противодействие преступлениям экстремистской направленности является одной из наибо- лее актуальных задач современности. Для ее решения активно используются разнообразные средства и методы, включая возможности, разработанные в настоящее время криминалистикой. Одним из перспектив- ных направлений в развитии совершенствования мер по противодействию экстремизму является формиро-}


вание нравственно ориентированной личности. В связи с этим целью исследования явилось рассмотрение возможностей осуществления воспитательного воздействия на свидетелей при производстве допроса по уголовным делам экстремистской направленности. Методы: методологическую основу данного исследования составили методы системности, анализа, историзма и сравнительно-правовой. Результаты: Обоснованная в работе авторская позиция базируется на рассмотрении возможностей использования воспитательного воздействия на различные категории свидетелей при производстве расследования по уголовным делам экстремистской направленности. При исследовании возможностей использования воспитательного воздействия была изучена взаимосвязь влияния личности следователя на личность свидетеля. На основании проведенного исследования проведена дифференциация характерных категорий свидетелей, подлежащих допросу по данной категории расследуемых уголовных дел. Исследовались особенности формирования профессиональных компетенций следователя и возможностей использования их ключевых элементов для осуществления позитивного воздействия на свидетелей. На основании анализа основ тактики допроса было определено место психологического контакта как элемента, способствующего усилить положительное воздействие на личность свидетеля при проведении допроса. Выводы: в результате исследования выявлена существующая взаимосвязь между воспитательным воздействием оказываемым следователем при производстве допросов свидетелей при расследовании преступлений экстремистской направленности. Установлено, что воспитательное воздействие может использоваться в качестве одной из мер противодействия преступлениям данного вида.

Ключевые слова: воспитательное воздействие, допрос свидетеля, информация, психологический контакт, расследование преступлений, свидетель, следователь.

Цитирование. Славгородская О. А. Реализация воспитательной функции допроса свидетеля как элемента противодействия преступлениям экстремистской направленности // Legal Concept = Правовая парадигма. -2020. - Т. 19, № 2. -C. 64-70. - DOI: https://doi.org/10.15688/lc.jvolsu.2020.2.9

\section{Введение}

Слово «экстремизм», согласно Большому энциклопедическому словарю, происходит от латинского слова «еxtremus» и означает приверженность к крайним мерам [8, с. 1395]. Крайняя степень реализации чего-либо всегда приводит к необратимым последствиям, в связи с чем противодействие экстремисткой деятельности является одной из ключевых задач современности.

В Российской Федерации реализация мероприятий, направленных на противодействие экстремистской деятельности, осуществляется в первую очередь в соответствии с Федеральным законом от 25.07.2002 № 114-ФЗ (ред. от 02.12.2019) «О противодействии экстремистской деятельности» (Закон), предусматривающим также наряду с многоуровневыми мерами противодействия осуществление и профилактической деятельности.

Профилактическую деятельность в соответствии со ст. 5 Закона составляют в том числе и меры воспитательного характера. Воспитательное воздействие как элемент противодействия экстремистской деятельности реализуется в самых разнообразных направлениях, поскольку воспитательная деятельность про- низывает практически любые сферы жизни общества. Не является исключением и деятельность, осуществляемая в процессе раскрытия, расследования и предотвращения преступлений экстремистской направленности.

В свое время еще известный советский процессуалист Ц.М. Каз, определяя цели уголовного судопроизводства, указывала, что они состоят не только в достижении истины и обеспечении законности, защите прав и законных интересов участников процесса, но и в воспитательном воздействии [6, с. 18].

Ученый обращала внимание на то, что воспитательные цели рассматриваются как перспективные и не исчерпываются в уголовном судопроизводстве [6, с. 30]. Оценивая взаимосвязь уголовного судопроизводства с решением иных задач воспитательного характера необходимо отметить, что существует связь реализуемого им правового воспитания с нравственным.

Существование подобной взаимосвязи были отмечено и авторами работы «Судебная этика» Г.Ф. Горским, Л.Д. Кокоревым, Д.И. Котовым. По их справедливому мнению нравственное воспитание способствует формированию у лица совокупности моральных принципов и правил поведения, сле- 
дуя которым оно в любой ситуации принимает решение, соответствующее нормам морали [3, с. 184].

Следовательно, продолжение реализации мер воспитательного воздействия, осуществляемого в сфере уголовного судопроизводства, можно экстраполировать на решение задач нравственного совершенствования, оценивая его в свою очередь как основу для формирования личности, способной противостоять влиянию идей экстремистской направленности.

\section{Анализ роли \\ воспитательного воздействия \\ допроса свидетелей \\ в противодействии экстремизму}

Состояние экстремистской направленности Е.П. Сергун определяет как особое состояние психики, для которого характерна направленность личности, психологически готовой к совершению на почве антидемократических, антиконституционных воззрений совершать уголовно-наказуемые деяния [9, с. 15].

Следовательно, ключевую роль в воспитании личности с развитым правосознанием и высоким уровнем нравственных ценностей играет деятельность, оказывающая противодействие противоправному поведению, причем на всех этапах, включая процесс раскрытия и расследования преступлений. Воспитательные задачи по формированию нравственных основ личности, решаемые в сфере уголовного судопроизводства, реализуются в отношении различных его субъектов, причем в непосредственной взаимосвязи.

Одной из категорий субъектов, подвергающихся непосредственному воспитательному воздействию при расследовании преступлений экстремистской направленности, являются свидетели. При расследовании подобной категории преступлений значительный объем информации удается получить посредством многочисленных допросов свидетелей.

Классифицируя виды свидетелей, допрашиваемых по данной категории уголовных дел, следует в первую очередь выделить лиц, способных сообщить информацию относительно личности обвиняемых, указать на степень сформированности у данных лиц определен- ных убеждений, взглядов и позиций, а также раскрыть содержание обстоятельств, под влиянием которых и происходило становление позиции экстремистской направленности.

Поскольку процессы формирования указанного состояния психики имеют протяженность во времени, то выявление всех периодов и характеристика каждого из них возможны при целенаправленном сборе информации о круге общения, связях, интересах обвиняемого лица и получения в результате этого наиболее полной картины становления и развития подобной преступной мотивации.

При этом задача получения подобной информации не всегда может быть решена без предварительной организации условий для ее получения. Это основывается на том, что лица, которые подобной информацией располагают, не стремятся поделиться ею со следователем или даже скрывают свою осведомленность. Они не раскрывают данных о своем знакомстве с обвиняемым, зачастую ссылаются на то, что оно носило случайный, кратковременный характер.

Формирование возможностей получения соответствующей информации требует от следователя реализации воспитательной функции путем создания позитивного образа представителя власти как при расследовании уголовных дел любого уровня сложности, так и несомненно в ситуации, когда речь идет о расследовании преступлений экстремистской направленности.

Следователь, решая задачи по установлению и доказыванию всех обстоятельств совершенного преступления, всегда должен ориентироваться на обязательное определение значения доказательств, которое может варьироваться в зависимости от объема той информации, которую непосредственно можно извлечь из факта, и от того, какую роль способна сыграть данная информация в установлении истины $[1$, с. 84].

Специфичность экстремистской деятельности при расследовании преступлений данного вида требует от следователя проявления максимального набора профессиональных качеств, состоящего в реализации через взаимодействие с участниками расследования нравственной составляющей, сочетающейся с выполнением своего профессионального долга. 
Особое значение в процессе общения со свидетелями по данной категории уголовных дел приобретают базовые профессиональные качества следователя. Он должен сочетать в себе совокупность различных качеств личности и, помимо профессиональных, обладать соответствующими идейными качествами, к которым можно отнести уровень культуры и чувство долга. Кроме того, необходимы нравственно-психофизиологические качества, состоящие в следовании чувству справедливости и устойчивости к профессиональной деформации.

В совокупности все требования к личности следователя реализуются в том, что «нравственные нормы поведения следователя всегда выступают как своеобразное единство должного и реального, как частичка его нравственного сознания и как результат его нравственной практики» [5, с. 133, 136].

Ориентируясь на вышеназванные нравственные нормы следователь должен уметь сохранять беспристрастность по отношению к участникам процесса и не поддаваться личным отношениям к участникам процесса, иначе он может попасть под влияние обвинительного или оправдательного уклона, а это приведет к нарушению процесса доказывания по делу [10, с. 140].

Осознанное создание у свидетеля представления о сопричастности следователя к событиям, не имеющим к нему непосредственного отношения и не затрагивающим его лично, способствуют формированию у свидетеля представления о высоком уровне правосознания и нравственности следователя, и соответственно подобное позитивное отношение содействует тому, что свидетели оказываются готовы пойти на установление психологического контакта со следователем.

\section{Содержание психологического контакта при допросе свидетелей}

Понятие психологического контакта является одним из наименее проработанных в теории криминалистики. Подобная ситуация требует определения однозначности категории. Целесообразным представляется преобладание в ее содержании создания обстанов- ки, способствующей общению следователя с допрашиваемым. Место и роль психологического контакта в структуре допроса также определены не достаточно четко. При этом преобладает мнение, что психологический контакт составляет основу успешного производства допроса [4, с. 277]. Не является исключением и допрос свидетеля. При установлении психологического контакта формируется уровень взаимоотношений на допросе, при котором участвующие в нем лица готовы воспринимать исходящую друг от друга информацию [13, с. 489].

Рассматривая психологический контакт в качестве непременного условия допроса, профессор Н.И. Порубов определяет его как «состояние, при котором люди могут и желают воспринимать информацию, исходящую друг от друга» [7, с. 47]. Его формирование неразрывно связано с заинтересованностью в информации или в лице, который выступает в качестве ее источника. «Заинтересованность - первый элемент психологического контакта. Это эмоционально окрашенная направленность личности, связанная со стремлением познать, насколько значима информационная связь для другого индивида...» $[11$, с. 14$]$.

Определение стадий развития контакта основано на выделении следующих взаимообусловливающих стадий: 1) взаимное оценивание; 2) взаимная заинтересованность; 3) обособление в диаду [12, с. 201]. Оценивая возможность использования названной характеристики применительно ситуации формирования психологического контакта при производстве допроса свидетеля, необходимо учитывать особенные условия его реализации, изначально предполагающие обособленность участников.

Состояние обособленности самих участников допроса должно быть максимально использовано следователем как основа для дальнейшего благоприятного формирования психологического контакта. В связи с этим необходимо, базируясь на состоянии обособленности, максимально использовать данное состояние при организации допроса свидетеля и в обстановке его проведения создавать благоприятную среду. «Для установления контакта важно, чтобы допрос производился наедине. В этом имеется глубокий психологи- 
ческий смысл. Контакт при допросе предполагает элемент доверительности» [7, с. 54-55]. В остальном же развитие процесса установления психологического контакта происходит в рамках классической схемы.

Следовательно, ключевым элементом формирования психологического контакта при допросе свидетеля является то, как воспринимает сам допрашиваемый внутреннюю обстановку, которая складывается в процессе производства данного следственного действия. Процесс формирования психологического контакта можно реализовывать на различных стадиях производства допроса и на основе разнообразных тактических приемов.

При установлении психологического контакта со свидетелем следователю необходимо получить не только максимально полные показания относительно расследуемого преступления, но и представление о мировоззрении свидетеля, его взглядах и установках. При выявлении фактов предварительной ориентированности на формирование взглядов экстремистской направленности следователю необходимо в рамках проведения допроса предпринять попытку по переориентации взглядов свидетеля. Достигнуть цели возможно посредством приведения примеров последствий преступлений экстремистской направленности, проводя исторические параллели и используя силу аргументации и убеждений.

В отношении еще одной группы свидетелей реализация воспитательного воздействия сталкивается, как правило, с серьезными затруднениями. Речь идет о лицах, которые допрашиваются в качестве свидетелей, фактически сами будучи активно вовлеченными в преступную деятельность [2, с. 50]. Со стороны указанной категории лиц противодействие реализуется часто в открытой форме и направлено на затруднение получения следователем информации относительно характера идеологии группы экстремистской направленности, ее численности, длительности существования, структуры организации, совершения ею определенных преступных актов и т. п. Проведение допросов подобных лиц осуществляется в конфликтных ситуациях и характеризуется высоким уровнем проявления противодействия.
Роль следователя при проведении допросов данной категории свидетелей состоит в создании у допрашиваемых уверенности, что все факты экстремистской деятельности будут выявлены, установлены и доказаны. Формированию подобной убежденности должно способствовать профессиональное проведение допросов, основанных на тщательной подготовке; выстраивание логической последовательности задаваемых вопросов, подкрепляемых при необходимости доказательствами и т. п.

\section{Выводы}

Воспитательное воздействие, реализуемое в процессе допросов свидетелей при расследовании преступлений экстремисткой направленности, следует использовать в качестве эффективной меры профилактического характера. В целях повышения уровня противодействия преступлениям экстремистской направленности при производстве допросов следователям необходимо реализовать совокупность профессиональных качеств, позволяющих создавать положительный образ сотрудника правоохранительных органов и оказывающий правовое воздействие на свидетелей. Следует широко использовать криминалистические приемы, направленные на установление психологического контакта. В сложных ситуациях, характеризующихся высоким уровнем противодействия со стороны свидетелей, необходимо применять совокупность традиционных тактических приемов реализуемых в подобных ситуациях.

\section{СПИСОК ЛИТЕРАТУРЫ}

1. Белкин, Р. С. Собирание, исследование и оценка доказательств / Р. С. Белкин. - М. : Наука, 1966. $-295 \mathrm{c}$.

2. Выстропов, В. Г. Общие положения проведения допросов при расследовании преступлений, связанных с организацией экстремистской деятельности / В. Г. Выстропов // Вестник Восточно-Сибирского института МВД России. - 2017. - № 4 (83). C. $45-52$.

3. Горский, Г. Ф. Судебная этика / Г. Ф. Горский, Л. Д. Кокорев, Д. П. Котов. - Воронеж : Изд-во Воронежского ун-та, 1973. - 271 с. 
4. Зеленский, В. Д. Криминалистика : учебник / В. Д. Зеленский ; под ред. В. Д. Зеленского, Г. М. Меретукова. - СПб. : Юридический центр, 2015 - 704 с.

5. Игнатов, С. Д. Требования, предъявляемые к личности следователя / С. Д. Игнатов // Вестник Удмуртского университета. - 2014. - Вып. 2. C. 133-140.

6. Каз, Ц. М. Проблемы доказывания в суде первой инстанции. Цели доказывания / Ц. М. Каз. Саратов : Изд-во Сарат. ун-та, 1978. - 79 с.

7. Порубов, Н. И. Допрос в советском уголовном процессе и криминалистике / Н. И. Порубов. Минск : Вышэйшая школа, 1968. - 276 с.

8. Прохоров, А. М. Большой энциклопедический словарь / А. М. Прохоров. - 2-е изд., перераб. и доп. - М. : Большая Российская энциклопедия ; СПб. : Норинт, 2001. - 1456 с.

9. Сергун, Е. П. Экстремизм в российском уголовном праве : автореф. дис. ... канд. юрид. наук : 12.00 .08 / Сергун Евгений Петрович. - Тамбов, $2009 .-24 \mathrm{c}$.

10. Татьянина, Л. Г. Нравственные начала деятельности следователя / Л. Г. Татьянина // Судебная власть и уголовный процесс. - 2015. - № 4. C. $137-140$.

11. Хайдуков, Н. П. Тактико-психологические основы воздействия на участвующих в деле лиц / Н. П. Хайдуков. - Саратов : Изд-во Сарат. ун-та, 1984. -128 с.

12. Чуфаровский, Ю. В. Юридическая психология / Ю. В. Чуфаровский. - М. : Проспект, 2013. $-470 \mathrm{c}$.

13. Яблоков, Н. П. Криминалистика : учебник / Н. П. Яблоков. - 3-е изд., перераб. и доп. - М. : Юристь, 2005. - 781 с.

\section{REFERENCES}

1. Belkin R.S. Sobiraniye, issledovaniye $i$ otsenka dokazatelstv [Collection, Research and Assessment of Evidence]. Moscow, Nauka Publ., 1966. $295 \mathrm{p}$.

2. Vystropov V. G. Obshchiye polozheniya provedeniya doprosov pri rassledovanii prestupleniy, svyazannykh s organizatsiey ekstremistskoy deyatelnosti [General Provisions for Interrogations in the Investigation of Crimes Related to the Organization of Extremist Activities]. Vestnik Vostochno-Sibirskogo instituta MVD Rossii [Vestnik of the East Siberian Institute of the MIA of Russia], 2017, no. 4 (83), pp. 45-52.

3. Gorsky G.F. Sudebnaya etika [Judicial Ethics]. Voronezh, Publishing House of Voronezh University, $1973.271 \mathrm{p}$.

4. Zelensky V.D. Kriminalistika: uchebnik [Criminalistics: Textbook]. Saint Petersburg, Publishing House Legal Center, 2015. 704 p.

5. Ignatov S.D. Trebovaniya, predyavlyayemyye $\mathrm{k}$ lichnosti sledovatelya [Requirements for the Identity of the Investigator]. Vestnik Udmurtskogo universiteta [Bulletin of the Udmurt University], 2014, iss. 2, pp. 133-140.

6. Kaz C.M. Problemy dokazyvaniya v sude pervoy instantsii. Tseli dokazyvaniya [Problems of Evidence in the Trial Court. The Purpose of Evidence]. Saratov, Publishing House of Saratov University, 1978. 79p.

7. Porubov N.I. Dopros v sovetskom ugolovnom protsesse i kriminalistike [Interrogation in the Soviet criminal trial and forensics]. Minsk, Higher School, 1968. $276 \mathrm{p}$.

8. Prokhorov A.M. Bolshoy entsiklopedicheskiy slovar [Great Encyclopedic Dictionary]. Moscow, Big Russian Encyclopedia; Saint Petersburg, Norint, 2001. 1456 p.

9. Sergun E.P. Ekstremizm v rossiyskom ugolovnom prave: avtoref. dis. ... kand. yurid. nauk: 12.00.08 [Extremism in the Russian Criminal Law. Cand. yurid. sci. abs. diss.].Tambov, 2009. 24 p.

10. Tatyana L.G. Nravstvennyye nachala deyatelnosti sledovatelya [Moral Principles of the Investigator]. Sudebnaya vlast $i$ ugolovnyy protsess [The Judiciary and the Criminal Process], 2015, no. 4, pp. 137-140.

11. Khaidukov N.P. Taktiko-psikhologicheskiye osnovy vozdeystviya na uchastvuyushchikh $v$ dele lits [The Tactical and Psychological Basis of the Impact on the Persons Involved in the Case]. Saratov, Publishing House of Saratov University, 1984. $128 \mathrm{p}$.

12. Chufarovsky Yu.V. Yuridicheskaya psikhologiya [Legal Psychology]. Moscow, Prospect Publ., 2013.470 p.

13. Yablokov N.P. Kriminalistika: uchebnik [Criminalistics: Textbook]. Moscow, Lawyer Publ., 2005. $781 \mathrm{p}$. 


\section{Information About the Author}

Olga A. Slavgorodskaya, Candidate of Sciences (Jurisprudence), Associate Professor, Department of Criminology, Saratov State Academy of Law, Volskaya St., 1, 410056 Saratov, Russian Federation, slavkur-htc@yandex.ru, https://orcid.org/0000-0001-6652-0744

\section{Информация об авторе}

Ольга Александровна Славгородская, кандидат юридических наук, доцент кафедры криминалистики, Саратовская государственная юридическая академия, ул. Вольская, 1, 410056 г. Саратов, Российская Федерация, slavkur-htc@yandex.ru, https://orcid.org/0000-0001-6652-0744 